\title{
The Role of Peripheral Cannabinoid Receptors Type 1 in Rats With Visceral Hypersensitivity Induced by Chronic Restraint Stress
}

\author{
Lei Shen, MD, Xiao-jun Yang, MD, Wei Qian, MD and Xiao-hua Hou, MD* \\ Division of Gastroenterology, Union Hospital of Tongji Medical College, Huazhong University of Science and Technology, Wuhan, China
}

\section{Background/Aims}

This study was designed to investigate the possibility that the enhanced nociceptive responsiveness associated with canabonoid type 1 receptors (CB1Rs) and identify its role in mediating visceral hypersensitivity induced by chronic restraint stress.

\section{Methods}

Rats were exposed to daily partial restraint stress or sham partial restraint stress with intraperitoneal injection of the vehicle, CB1R agonist or antagonist for 4 consecutive days. We tested the visceromotor reflex to colorectal distention at day 0 and 5. Reverse-transcription polymerase chain reaction and Western blot were used to assess the expression of CB1Rs.

\section{Results}

Intraperitoneal CB1 agonist (ACEA) injection significantly diminished $(p<0.05)$ the enhanced visceromotor reflex to colorectal distention at day 5 in stressed rats. Change in electromyogram response after ACEA over baseline, at pressure of $40 \mathrm{mmHg}$ $(+13.3 \pm 2.2), 60 \mathrm{mmHg}(+15.3 \pm 2.8)$ and $80 \mathrm{mmHg}(+17.0 \pm 4.0)$ were much lower than in the control animals, which were $+35.9 \pm 5.1,+41.1 \pm 6.3$ and $+54.1 \pm 9.6$, respectively. Whereas, CB1 antagonist (SR141716A) had an opposite effect. Compared with control group, the change in electromyogram response after SR141716A over baseline was significantly enhanced $(p<0.05)$ for the distending pressure of $40 \mathrm{mmHg}(+56.0 \pm 10.3), 60 \mathrm{mmHg}(+74.6 \pm 12.3)$ and $80 \mathrm{mmHg}(+82.9$ \pm 11.0 ), respectively. Reverse-transcription polymerase chain reaction and Western blotting demonstrated the stress-induced up-regulation of colon CB1Rs $(p<0.05)$.

\section{Conclusions}

Our results suggest there is a key contribution of peripheral CB1Rs involved in the maintenance of visceral hyperalgesia after repeated restraint stress, providing a novel mechanism for development of peripheral visceral sensitization.

\section{(J Neurogastroenterol Motil 2010;16:281-290)}

\section{Key Words}

Irritable bowel syndrome; Receptor, Cannabinoid, CB1; Stress disorders; Hyperalgesia

Received: May 9, 2010 Revised: June 23, 2010 Accepted: July 2, 2010

(c) This is an Open Access article distributed under the terms of the Creative Commons Attribution Non-Commercial License (http://creativecommons. org/licenses/by-nc/3.0) which permits unrestricted non-commercial use, distribution, and reproduction in any medium, provided the original work is properly cited.

*Correspondence: Xiao-hua Hou, MD

Division of Gastroenterology, Union Hospital of Tongji Medical College, Huazhong University of Science and Technology, 1277 Jiefang Road, Wuhan 430022, China

Tel: +86-27-8572-6930, Fax: +86-27-8572-6930, E-mail: Houxh@public.wh.hb.cn

Financial support: This study was founded by the National Natural Science Fund (NNSF 30670957).

Conflicts of interest: None. 


\section{Introduction}

For centuries, different preparations of Cannabis plants have been used for the treatment of gastrointestinal (GI) disorders such as spasmic pain, gastroenteritis and diarrhea. ${ }^{1}$ Nowadays, a growing body of literature indicates substances acting on cannabinoid receptors alter secretion and motility of the gut, ${ }^{2,3}$ and have antinociceptive or antihyperalgesic properties. ${ }^{4}$ This makes them an attractive target for GI functional disorders, such as irritable bowel syndrome (IBS). IBS is a typical of such disorders, which have visceral sensitivity, autonomic nervous system dysfunction and can be induced by mental stress . So we associated those factors into our experiment, tried to figure out whether interfering into the mental stress can remedy the stress induced visceral hypersensitivity. ${ }^{5}$ Upon external psychological stress insults, several different cellular pathways are activated in the intestinal tract, leading to a pathological state. ${ }^{6}$ And, the discovery of the endogenous cannabinoid (endocannabinoid) system ${ }^{7}$ provided new insights into a neuromodulatory scheme, portends better explanations, and treatments for, a wide variety of previously intractable disorders, particularly painful conditions, ${ }^{8,9}$ were promising.

Recent evidence obtained in model of neuropathic pain showed greater effects of cannabinoids reducing sensitivity to pain and boosting endurance, strongly suggesting cannabinoid receptors have capable of anti-nociceptive. ${ }^{10}$ Based on cumulated literature of searches about involvement of cannabinoid system in the pathophysiology of IBS, an underlying clinical endocannabinoid deficiency that implicated a plausible target for novel therapies for IBS was suggested. ${ }^{11}$ In animal model, experiment muscle tone has been demonstrated to be under tonic endocannabinoid control, ${ }^{12}$ especially in treatment of spasticity, cannabis extracts have already proven efficacious. ${ }^{13,14}$ To date, two cannabinoid receptors have been isolated and cloned. Activation of cannabinoid type 1 receptors (CB1Rs) was shown to modulate several functions in the GI tract, including gastric secretion, gastric emptying and intestinal motility, ${ }^{15}$ while CB2Rs are mainly located in immune cells.

Cannabinoid act at many points within the brain-gut axis, influencing GI activity through their actions centrally or on extrinsic primary afferent nerves. Among the roles of the endocannabinoid system at different level, its analgesic action at spinal and peripheral levels has been largely documented. ${ }^{4}$ Outside of the CNS, high densities of CB1Rs are found in the enteric nerv- ous system, sympathetic and sensory nerve, which suggests the essential effects of cannabinoids in the peripheral primary afferent. These effects are often different from those mediated by actions directly on the enteric nervous system. So it's meaningful to investigate the involvement of CB1Rs in the peripheral. It has been shown that action of CB1 attenuates colonic-inflammation induced visceral hyperagesia. ${ }^{16}$

Recently, chronic intestinal inflammation model experiment reports the up-regulation or sensitization of cannabinoid receptors in the small intestine, ${ }^{17}$ but the antihyperalgesic action of cannabinoid is not well established. Only a limit numbers of studies indicated the modulation role of CB1Rs in non-inflammatory visceral hypersensitivity model. CB1Rs mediating the analgesic effect on visceral pain induced by colorectal distension was shown in a recent research. ${ }^{18}$ It might helpful to determine whether there are any changes in CB1Rs expression associated with underlying pathology. In the present investigation, we examined the role of the CB1Rs after partial restraint stress insults in the colon and indicated this system provides intrinsic protection against stress induced visceral hyperalgesia.

\section{Materials and Methods}

\section{Animals}

Adult male Sprague-Dawley rats (250-275 g) were purchased from Experimental Animal Center of Tongji Medical School (Wuhan, P. R. China). Animals were maintained on a normal light-dark cycle, housed in pairs or singlely, and were kept in a regulated environment $\left(20-25^{\circ} \mathrm{C}\right)$. They were provided with food and water ad libitum. All protocols were approved by the Animal Care and Use Committee of Union Hospital of Tongii Medical College. All experiments were performed during the same period of the day (between 10:00 and 12:00) to minimize any influence of circadian rhythms.

\section{Experimental design}

A total of 6 groups of 8 rats were included in this study. Acclimation to the experimental conditions was performed for 3 days preceding the start of the experiment. Each day, animals were transported to the testing room and placed for 30 minutes in the Plexiglas cylinders used for colorectal distension (CRD) experiments. On day 0, a baseline response to CRD was evaluated (CRD \# 1). From day 1 to day 4, rats were submitted daily to either 2-hour partial restramint stress (PR) for the stress group 
or to 2-hour sham PR for the control group, Then the response to CRD was measured again at day 5 (CRD \#2), and in order to check for the acute involvement of $\mathrm{CB} 1$ on visceral hyperalgesia, the rats were treated with $\mathrm{CB} 1 \mathrm{R}$ agonist, antagonist or vehicle. If the endogenous cannabinoid system plays an important role in the visceral sensory pathway protection from PR induced visceral hyperalgesia, it is conceivable that activation or block of cannabinoid receptors during CRD process might diminish or exacerbate the hypersensitivity. The different samples collected for reverse-transcription polymerase chain reaction (RT-PCR) and Western blotting analysis were taken from animals that had not undergone $\mathrm{CRD}$ to avoid the potential bias.

\section{Partial restraint stress procedure}

Stress effects were studied using the wrap PR model. ${ }^{19}$ Animals were lightly anaesthetized with ethyl ether, and their fore shoulders, upper forelimbs and thoracic trunk were wrapped in a confining harness of paper tape to restrict, but not to prevent, body movements. Then, the animals were placed in their home cage for 2 hours. The rats recovered from ethyl ether within 2-3 minutes and immediately moved about in their cages, with the restricted mobility of their forelimbs preventing grooming behavior. Control sham PR animals were anaesthetized but not wrapped and allowed to move freely in their cages. The PR at room temperature used here is a mild and non-ulcerogenic stressor which reproduces the symptoms associated with stress related colonic dysfunction in humans, suggesting that it may be a suitable model for studying the effect of stress on the GI tract.

\section{Visceral nociceptive response to chronic PR stress: effect of peripheral treatment with the CB1R agonist and antagonist}

The CB1R agonist ACEA [N-(2-Chloroethyl)-5Z, 8Z, 11Z, $14 \mathrm{Z}$ eicosatetraenamide] and CB1R antagonist SR141716A [N(Piperidin-1-yl)-5-(4-chlorophenyl)-1-(2,4-dichlorophenyl)4-methyl-1H-pyrazole-3-carboxamide], purchased from Tocris Cookson Inc (Bristol, UK) They were dissolved in vehicle solution (1 drop of Tween-80 in $3 \mathrm{~mL} \mathrm{2.5 \%} \mathrm{dimethylsulfoxide} \mathrm{in}$ saline) and injected 1 hour after the end of PR from day 1 to day 4. Vehicle solution was used in control experiments. ACEA, SR141716A and vehicle were tested in both chronically stressed and sham stressed animals. The dose of $5 \mathrm{mg} / \mathrm{kg}$ and $3 \mathrm{mg} / \mathrm{kg}$ body weight was selected based on published reports respectively. ${ }^{20,21}$

\section{Assessment of visceromotor response to colorectal distention}

\section{1) Colorectal distention}

Taking former as standard, the stimulus was induced by distention of descending colon and rectum, which has been established available, our procedure was after the formula. ${ }^{22}$ Animals were lightly anesthetized with halothane, then a pair of silver electrodes was pricked into the external oblique muscle, just superior to the inguinal ligament and inflexible plastic balloon $(7 \mathrm{~cm}$ long and $2 \mathrm{~cm}$ wide) lubricated with liquid paraffin oil (Sigma, MO, USA) was inserted intra-anally into the descending colon (after the distal part of the rectum was gently cleared by massage), positioned with the tip $1 \mathrm{~cm}$ proximal to the anus, and secured in place by taping the balloon catheter to the base of tail. Once recovered from anesthesia, animals equipped with the balloon were placed in a Plexiglas cylinder for 30 minutes before the CRD procedure was initiated. Electromyogram (EMG) recording was done as follows: 20 seconds before CRD (baseline), 20 seconds during CRD and 20 seconds after termination of CRD. Each intensity grade of phasic CRD (20, 40, 60 and $80 \mathrm{mmHg}$ ) lasted 20 seconds and interval of stimulus was 4 minutes; each pressure was tested 3 times.

\section{2) Recording}

The catheter, which was fixed a balloon on one end, was then connected to an air pump via a $\mathrm{Y}$ connector on the other end. The balloon pressure, which represents intracolonic pressure, was continuously monitored online with a computer. EMG activity surpassing the preset threshold value 300 IV during the balloon inflation period was amplified, filtered (1,000-4,000 Hz), and digitized (sampling at $200 \mathrm{~Hz}$ ) using a program written in RM6240B (Chengdu Instruments, Sichuan, China). The EMG was quantified with frequency. Results are presented as the means $\pm \mathrm{SD}$. Animals showing an EMG signal/noise ratio < 0.05 were excluded from the study.

\section{Collection of distal colon, proximal colon, and distal small intestinal samples for CB1R expression analysis}

The different samples collected for molecular analysis were taken from animals that had not undergone surgery or CRD to avoid the potential bias that this procedure may induce regarding neurotransmitter production or release. Animals were subjected either to PR or sham PR stress for 2 hours daily for 4 consecutive days. On day 5, animals were killed, distal colon positioned with the tip $1 \mathrm{~cm}$ proximal to the anus, proximal colon positioned $1 \mathrm{~cm}$ 
distant from ileocecal junction and distal intestinal positioned 1 $\mathrm{cm}$ proximal to the ileocecal junction. And then segments $2-3 \mathrm{~cm}$ long of distal colon, proximal colon and distal small intestine were quickly removed and then placed either in RNA later solution for RT-PCR experiments or frozen on dry ice for Western blotting analysis.

\section{1) Detection of CB1R messenger RNA expression}

Preparation: Weighted $50 \mathrm{mg}$ tissues of each species, and then homogenized in $1 \mathrm{~mL}$ of TRIzol Reagent (Invitrogen Inc, Carlsbad, CA, USA). Incubated the homogenized samples to $15^{\circ} \mathrm{C}$ for 5 minutes in eppendorf tubes. Added $0.2 \mathrm{~mL}$ chloroform into each eppendorf tube. Caped the tubes and shaked vigorously by hand for 15 seconds and then incubated them to $15^{\circ} \mathrm{C}$ for 3 minutes. Centrifugated at $12,000 \times \mathrm{g}$ for 15 minutes at $4^{\circ} \mathrm{C}$. Transfered the colorless upper aqueous phase to a fresh new tube. Then added $0.5 \mathrm{~mL}$ of isopropyl alcohol into each tube, incubated to $15^{\circ} \mathrm{C}$ for 10 minutes. Centrifugated at $12,000 \times \mathrm{g}$ for 10 minutes at $4^{\circ} \mathrm{C}$. A gel-like pellet on the side and bottom of the tube visible was RNA. Removed the supernatantand Washed the RNA with $1 \mathrm{~mL}$ of $75 \%$ ethanol, and then centrifuged at 7,500 $\times \mathrm{g}$ for 5 minutes at $4^{\circ} \mathrm{C}$. Air dried the RNA. The RNA was dissolved in $10 \mu \mathrm{L}$ RNase-free water and measured by spectrophotometer analysis at $260 \mathrm{~nm}$.

\section{(1) Reverse transcriptase}

Added $2 \mu \mathrm{g}$ of RNA and $0.5 \mu \mathrm{g}$ of Oligo $\mathrm{dT}_{18}$, and ribonuclease-free water to a final volume of $10 \mu \mathrm{L}$. Tubes were heated to $70^{\circ} \mathrm{C}$ for 5 minutes and then fast cooled on ice to prevent secondary structure from reforming. Then spined briefly to collect the solution at the bottom of the tube. RNA was transcribed to cDNA by a reverse transcriptase in a total $25 \mu \mathrm{L}$ RT reaction solution containing $5 \mu \mathrm{L} 5 \times$ Reverse Transcriptase Buffer, $5 \mu \mathrm{L}$ dNTP (10 mM each, Promega, Shanghai, China) 25 unites RNase Inhibitor, 200 units MMLV-RTase (Promega). Shaked up the mixture, and then incubated it to $37^{\circ} \mathrm{C}$ for 60 minutes for random primers.

\section{(2) Polymerase chain reaction}

The system was composed of $15.9 \mu \mathrm{L} \mathrm{H}_{2} \mathrm{O}, 0.3 \mu \mathrm{L}$ of forward primer, $0.3 \mu \mathrm{L}$ of reverse primer, $1.0 \mu \mathrm{L}$ dNTP, $2.5 \mu \mathrm{L}$ $\mathrm{Mg}^{2+} 2.5 \mu \mathrm{L}$ of $10 \times$ Buffer, $2.0 \mu \mathrm{L}$ of cDNA and $0.5 \mu \mathrm{L}$ of Taq DNA polymerase in a total volume of $25 \mu \mathrm{L}$. The primer of CB1R was 5'-CCTGGTTCTGATCCTGGTGG-3'; 5'-GTTGTTGGCGTGCTTGTGC-3' (283 bp, gi: 52421334). And the primer of $\beta$-actin was 5'-AGGGAAATCGTGCGTGAC-3'; 5'-ACCCAGGAAGGAAGGCT-3' (189 bp, gi:13592132). They were designed by primer 5.0. The reaction condition was first $95^{\circ} \mathrm{C}$ for 5 minutes to activate Taq DNA polymerase, followed by denaturation at $95^{\circ} \mathrm{C}$ for 30 seconds, annealing $57^{\circ} \mathrm{C}(\mathrm{CB} 1 \mathrm{R}) /$ $48^{\circ} \mathrm{C}$ ( $\beta$-actin) for 30 seconds and extension at $72^{\circ} \mathrm{C}$ for 30 seconds. The PCR was run for 35 cycles and finally elongated at $72^{\circ} \mathrm{C}$ for 7 minutes. The PCR products were detected by ethidium bromide staining on a $1 \%$ agarose gel, together with DNA Marker DL2000 (Takara, Dalian, China). And then total gray was evaluated by bandscan 4.3 (Glyko, Novato, CA, USA). The ratio of $\mathrm{CB} 1 \mathrm{Rs}$ and $\beta$-actin corresponding were recorded.

\section{2) Detection of $\mathrm{CB} 1 \mathrm{R}$ protein expression}

To minimize the error, standard the weight of tissue to 200 $\mathrm{mg}$. Tissues were homogenized in ice-cold lysis buffer solution $(\mathrm{pH} 7.4)$ containing a mixture of proteinase inhibitors $(50 \mathrm{mM}$ Tris- $\mathrm{HCl}, 100 \mathrm{mM} \mathrm{NaCl}, 15 \mathrm{mM}$ sodium pyrophosphate, 50 $\mathrm{mM}$ sodium fluoride, $1 \mathrm{mM}$ sodium orthovanadate, $5 \mathrm{mM}$ ethyleneglycol bis (2-aminoethylether) tetraacetic acid (EGTA), 5 $\mathrm{mM}$ ethylene diamine tetraacetic acid (EDTA), $1 \mathrm{mM}$ phenylmethylsulfonyl fluoride, $1 \mu \mathrm{M}$ microcystin-LR, $1 \mu \mathrm{M}$ okadaic acid, $0.5 \%$ TritonX-100, $2 \mathrm{mM}$ benzamidine, $60 \mu \mathrm{g} / \mathrm{mL}$ aprotinin and $60 \mu \mathrm{g} / \mathrm{mL}$ leupeptin) to avoid degradation of proteins. After centrifugation with $12,000 \times \mathrm{g}$ at $4^{\circ} \mathrm{C}$ for 10 minutes, the supernatant was then assayed for total protein concentration using the Bio-Rad Bradford Protein Assay it. Equal amounts of protein in sample buffer ( $1 \%$ sodium dodecyl sulfate, $10 \%$ glycerol, $100 \mathrm{mM}$ Tris, $0.05 \%$ biphenyl blue and 5\% 2-mercaptoethanol) were denatured, and then samples containing equal amount of protein were separated by $12 \%$ sodium dodecyl sulfate-polyacrylamide gel electrophoresis (SDS-PAGE) through electrophoresis and transferred to a polyvinyldine difluoride membrane. The membranes were blocked with in 5\% nonfat milk in Tri-buffered saline (TBS) containing 0.2\% Tween-20 (TBS-T) for 1 hour and were incubated with CB1R rabbit antiserum (catalog AB3558, Abcam, Cambridge, USA) at a final dilution (1:250) for overnight at $4^{\circ} \mathrm{C}$. Washed in TBS buffer three times for 10 minutes, incubated for 1 hour with goat anti-rabbit IgG conjugated with alkaline phosphatase (1:2,000, Sigma) in TBS-T, washed in TBS-T buffer three times for 10 minutes again, then incubated in chemiluminescent substrate solution (ECL, Pierce, Rockford, IL, USA). The blots were scanned and imported into the Image Pro program (5.1 version, Media Cybernetics, Bethesda, MD, USA) to measure the integral optical density of individual bands. The intensity of immunoreactive bands of interest was quantified and the data were normalized with the data of $\alpha$-actin of controls in the same blot. The same experiments were repeated three times, and results are presented as 
means $\pm \mathrm{SD}$

\section{Statistical methods}

EMG amplitudes were represented as percentage for the normalized reason. According to Bradesi's practice, is the percentage between highest and baseline distension. Then the value of each rat of groups will be averaged. ${ }^{23,24}$ The effect of stress and/or pharmacologic treatment on the EMG response to CRD within one group of animals was analyzed by comparing the post-stress or post-treatment measurements with the baseline or pretreatment values at each distention pressure using repeated-measures 2-way ANOVA followed by Bonferroni posttest comparisons. We have presented the data showing the EMG response at day 5 for rats treated with compound or vehicle expressed as the mean change from baseline for different pressures of distention. This method of analysis has been previously validated in a similar model of EMG measurement in response to CRD. ${ }^{24}$ These data were analyzed using Student's $t$ test.

Data for the expression of CB1Rs obtained from RT-PCR and Western blot between stressed and control groups were compared using an unpaired $t$ test.

\section{Results}

\section{Visceral hyperalgesia was reduced by administration of the potent cannabinoid agonist ACEA}

As shown in Figure 1A, ACEA abolished the stress-induced increase of the EMG compared with vehicle (Dunnett's test for multiple comparisons after ANOVA, $40 \mathrm{mmHg}, \mathrm{p}=0.028 ; 60$ $\mathrm{mmHg}, \mathrm{p}=0.036 ; 80 \mathrm{mmHg}, \mathrm{p}=0.007)$. ACEA application reduced the EMG response to a level similar to Sham-PR group (change in EMG response after ACEA over baseline, + $13.3 \pm$ 2.2 at $40 \mathrm{mmHg},+15.3 \pm 2.8$ at $60 \mathrm{mmHg}$ and $+17.0 \pm 4.0$ at $80 \mathrm{mmHg}$ ), while no significant effect ( $\mathrm{p}>0.05)$ of vehicle application was observed (change in EMG response after vehicle over baseline, $+35.9 \pm 5.1$ at $40 \mathrm{~mm} \mathrm{Hg},+41.1 \pm 6.3$ at 60 $\mathrm{mmHg}$ and $+54.1 \pm 9.6$ at $80 \mathrm{mmHg}$ ). Meanwhile, in the distension pressure of $20 \mathrm{mmHg}$, neither enhanced nor reduced response was shown.

To determine the effect of the CB1R agonist in controls, we tested the response to ACEA or vehicle injection in animals pre-
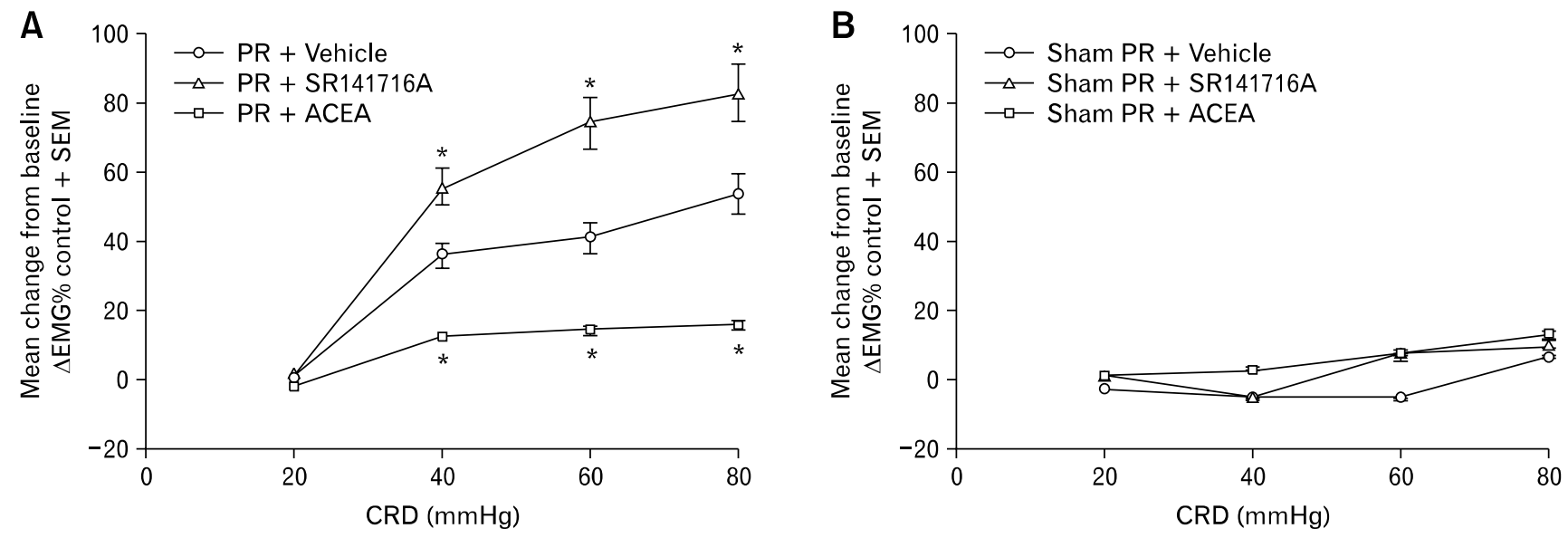

Figure 1. Effect of peripheral administration of the cannabinoid type 1 receptor (CB1R) agonist/antagonist on the electromyograpghy (EMG) to colorectal distension (CRD). (A) Effect of peripheral administration of the CB1R agonist/antagonist on the EMG to CRD of partial restraint stressed rats (day 5). EMG amplitude expressed as mean change from baseline after treatment with vehicle, ACEA or SR141716A in rats exposed to repeated partial restraint stress. Intraperitoneal injection of ACEA abolished the chronic stress-enhanced EMG to CRD compared with vehicle at the pressures of distention of 40,60 and $80 \mathrm{mmHg}$. Meanwhile, intraperitoneal injection of SR141716A had an exacerbated effect to the chronic stress-enhanced EMG to CRD compared with vehicle at the pressures of distention of 40, 60 and $80 \mathrm{mmHg}$. (B) Effect of peripheral administration of the CB1R agonist/antagonist on the EMG to CRD of sham PR rats (day 5). EMG amplitude expressed as mean change from baseline after treatment with vehicle, ACEA or SR141716A in rats exposed to chronic sham PR. ACEA or SR141716A did not affect the EMG response after chronic sham PR compared with vehicle. Data are expressed as mean $\pm \mathrm{SE}, \mathrm{n}=8$ in each group, ${ }^{*} \mathrm{p}<0.05$ significantly different compared with vehicle, 1-way ANOVA. 
Table 1. Change in Electromyogram Response Over Baseline of Control Groups

\begin{tabular}{lcccc}
\hline \multicolumn{1}{c}{ Groups } & $20 \mathrm{mmHg}$ & $40 \mathrm{mmHg}$ & $60 \mathrm{mmHg}$ & $80 \mathrm{mmHg}$ \\
\hline Sham PR + Vehicle & $-2.8 \pm 6.9$ & $-5.4 \pm 4.3$ & $-6.1 \pm 7.3$ & $6.1 \pm 3.2$ \\
Sham PR + SR141716A & $1.1 \pm 1.7$ & $-6.1 \pm 2.7$ & $7.4 \pm 5.8$ & $9.7 \pm 6.5$ \\
Sham PR + ACEA & $0.7 \pm 4.5$ & $2.9 \pm 2.3$ & $7.3 \pm 8.5$ & $12.6 \pm 3.4$ \\
p-value & 0.823 & 0.113 & 0.341 & 0.629 \\
\hline
\end{tabular}

PR, partial restraint stress; SR14716A, CB1 antagonist; ACEA, CB1 agonist. Data are presented as mean $\pm \mathrm{SD}$.

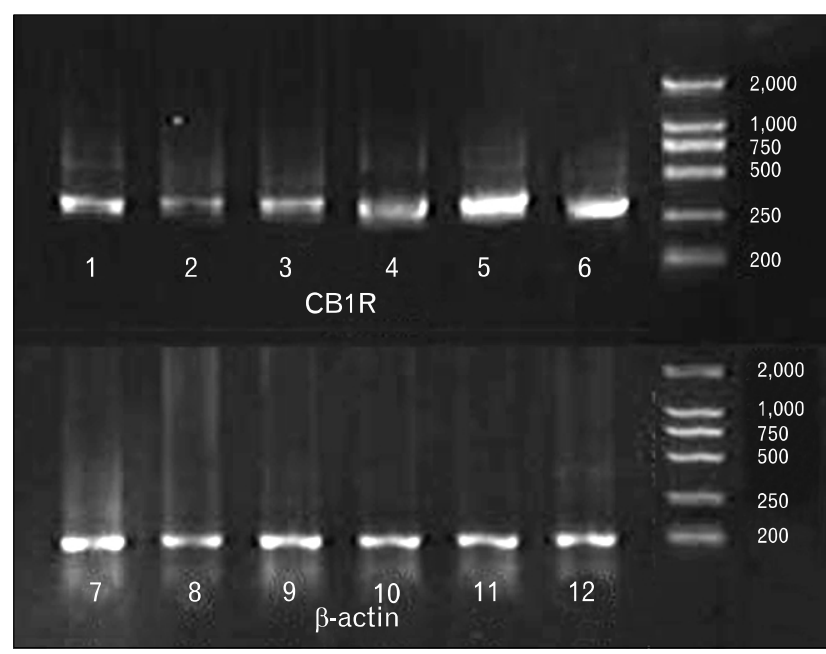

Figure 2. Representative reverse-transcription polymerase chain reaction (RT-PCR) for cannabinoid type 1 receptor $(\mathrm{CB} 1 \mathrm{R})$ in distal colon, proximal colon and distal small intestine. Band of 1,2 and 3 represent $\mathrm{PCR}$ for $\mathrm{CB} 1 \mathrm{R}$ in distal colon, proximal colon and distal small intestine from the rats of the sham partial restraint stress (PR) group; 4, 5 and 6 represent PCR for CB1R in distal colon, proximal colon and distal small intestine from the rats of the PR group. 7, 8 and 9 represent PCR for $\beta$-actin of controls in distal colon, proximal colon and distal small intestine from the rats of the sham PR group; 10,11 and 12 represent PCR for $\beta$-actin of controls in distal colon, proximal colon and distal small intestine from the rats of the PR group.

viously subjected to repeated sham PR. Compared with baseline, repeated exposure to sham $\mathrm{PR}$ had no significant effect on the EMG to CRD. As shown in Figure $1 \mathrm{~B}$ and Table 1, injection of vehicle or ACEA did not change the response to CRD.

\section{Pharmacological blockade of CB1 signaling increases severity of induced hypersensitivity}

Treatment with SR141716A induced stronger visceral hyperalgesia than treatment with vehicle. This was shown by the number of abdominal contractions to $\mathrm{CRD} \# 2$, for the distending pressure of $40 \mathrm{mmHg}(+56.0 \pm 10.3), 60 \mathrm{mmHg}(+74.6$

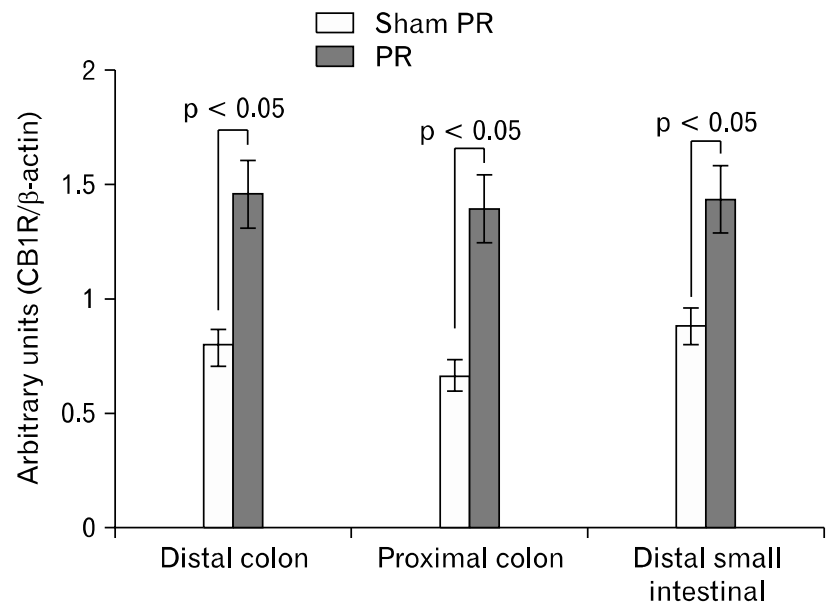

Figure 3. Expression of cannabinoid type 1 receptor (CB1R) in distal colon, proximal colon and distal small intestine following repeated partial restraint stress (PR). Levels of mRNA for CB1R measured by reverse-transcription polymerase chain reaction (RT-PCR). We observed a significantly higher level of CB1R mRNA in samples from chronic PR stress rats compared with control. Data are expressed as the relative CB1R PCR product to that of the housekeeping gene $\beta$-actin, mean \pm SEM, $n=8$ in each group.

$\pm 12.3)$ and $80 \mathrm{mmHg}(+82.9 \pm 11.0)(\mathrm{p}=0.047,0.008$ and 0.030 , respectively; Fig. $1 \mathrm{~A}$ ). It reveals a more severe visceral hypersensitivity in SR141716A-treated rats, with significant increase in numbers of abdominal contractions, as compared with vehicle-treated controls. In comparison with vehicle, for distending pressures of $20 \mathrm{mmHg}$, the compounds tested did not modify these EMG response induced by PR.

\section{PR Stress significantly enhanced CB1R expression}

\section{1) Semiquantitative RT-PCR for CB1R}

CB1R mRNA was expressed in the distal colon, proximal colon and distal small intestine, and the authenticity of the PCR product was verified by sequencing analysis (Fig. 2). We found significant increased expression for CB1R mRNA in samples from chronically partial restraint stressed animals compared with 


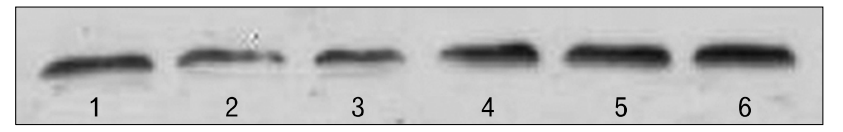

Figure 4. Representative Western blotting for cannabinoid type 1 receptor $(\mathrm{CB} 1 \mathrm{R})$ in distal colon, proximal colon and distal small intestine. The band of 1, 2 and 3 represent Western blotting for $\mathrm{CB} 1 \mathrm{R}$ in distal colon, proximal colon and distal small intestine from the rats of the sham partial restraint stress (PR) group; 4, 5 and 6 represent Western blotting for $\mathrm{CB} 1 \mathrm{R}$ in distal colon, proximal colon and distal small intestine from the rats of the PR group.

control (semiquantitative analysis, $0.79 \pm 0.13,0.66 \pm 0.10$ and $0.88 \pm 0.10$ in sham PR; $1.46 \pm 0.21,1.40 \pm 0.14$ and $1.44 \pm$ 0.17 in PR; p $=0.019,0.001$ and 0.013, respectively; Fig. 2 and $3)$.

\section{2) $\mathrm{CB1R}$ protein expression in intestine}

Western blot analysis in control and PR stress groups revealed a $\sim 60 \mathrm{kDa}$ band corresponding to the $\mathrm{CB} 1 \mathrm{R}$ protein (Fig. 4). Optical density analysis of blots showed significant higher expression of the $\mathrm{CB} 1 \mathrm{R}$ in the stress group compared with control $(p=0.0134)(0.70 \pm 0.11,0.67 \pm 0.08$ and $0.73 \pm$ 0.09 in sham PR; $1.35 \pm 0.28,1.15 \pm 0.17$ and $1.16 \pm 0.16$ in PR; $p=0.044,0.023$ and 0.035 , respectively). A $31 \%$ reduction was observed in the PR group compared with control (Fig. 5).

\section{Discussion}

The synchronous modulation between cannabinoid system and visceral hypergesia reflects a directly participation of cannabinoid system in the maintenance of physical sensation. Based on self-care and stress research, it is reasonable to propose that our bodies contain naturally occurring properties, including endocannabinoid auto-regulation, maintain our healthy such as stress reduction. ${ }^{25}$ These data show a protective role of the CB1Rs, indicating an early and important physiological step during self-protection of the stress-induced hypersensitivity.

\section{Pharmacology properties of CB1R in rats with visceral hyperalgesia induced by PR}

Pharmacological stimulation of cannabinoid receptors induced a reduction of experimental hyperalgesia, whereas selective antagonism of these receptors has the opposite effects, suggesting the presence of endocannabinoid tone. Previous reports have shown an inhibitory effect of different $\mathrm{CB} 1 \mathrm{R}$ agonists on visceral hyperalgesia in several animal models of peripheral colonic sensitization. For example, endocannabinoids exert a homeostatic

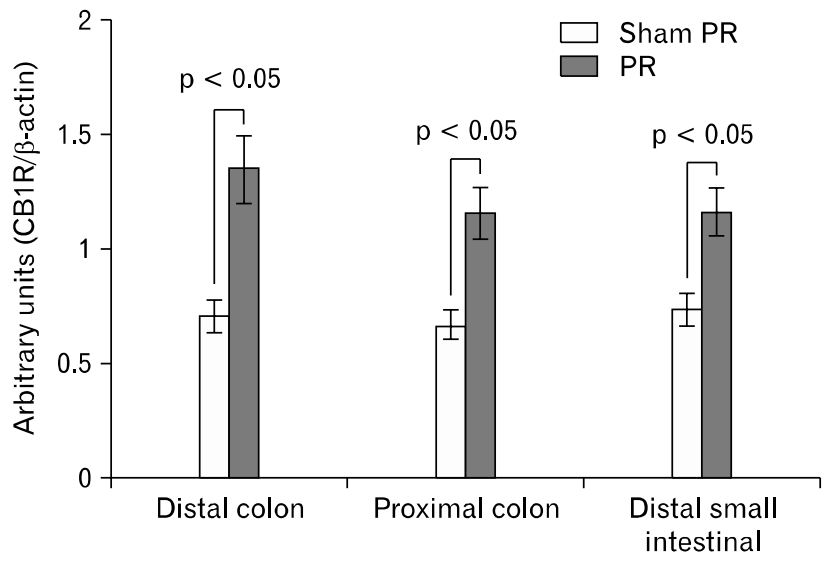

Figure 5. Expression of cannabinoid type 1 receptor $(\mathrm{CB} 1 \mathrm{R})$ in distal colon, proximal colon and distal small intestinal following repeated partial restraint stress (PR). Levels of $\mathrm{CB} 1 \mathrm{R}$ protein measured by Western blotting. A significant increase in the level of $\mathrm{CB} 1 \mathrm{R}$ protein in samples from chronic $\mathrm{PR}$ stress rats compared with control was observed. Data are expressed as normalized optical density, mean \pm SEM, $\mathrm{n}=8$ in each group.

function at the level of visceral perception, gut motility, inflammation and endothelial damage in inflammation. ${ }^{26-28} \mathrm{~A}$ collection of previously published material pointed to $\mathrm{CB} 1 \mathrm{R}$ play an important role in antihyperalgesic. Our findings support it and assume the process through visceral afferent pathway by control the expression of the receptors. The occurrence of hyperalgesia in the small or the large intestine is widely accepted. The balance between pro- and anti-visceral hyperalgesia within intricate surveillance network determines the outcome of the pathological processes of IBS. ${ }^{29}$ This result is consistent with previous reports during which colonic inflammation enhanced the antinociceptive action of $\mathrm{CB} 1 \mathrm{R}$ agonists, and activates an endogenous, CB1R mediated, antinociceptive pathway, ${ }^{16}$ suggesting a higher activation of gut endogenous cannabinoid system in the pathological state. Similar changes have been also previously reported in the setting of enhanced sensation models, in which repeated administration of cannabinoid agonist, through peripheral CB1Rs, produced a short- and longer- term attenuation of tumor-evoked hyperalgesia, ${ }^{30}$ and inflammation pain relieving. ${ }^{31}$

The decrease in sensitivity to $\mathrm{CRD}$ induced by the $\mathrm{CB} 1 \mathrm{R}$ agonist is supported by several anatomical data. CB1Rs, identified by western-blotting, have been shown to be involved in the noncholinergic control of intestinal motility. ${ }^{32}$ In a recent study, the stimulation or inhibition of CB1R alter the afferent intestinal nerve sensitivity to bradykinin, serotonin and noxious mechanical distension. ${ }^{33}$ Consistent with this hypothesis, contractility of 
smooth muscle to cholinergic or tachykinergic stimuli is increased in the early stages and decreased in the later stages of inflammation $^{34,35}$ which confirm the involvement of cannabinoid system, through neuro-mechanism, in the visceral hypersensitivity modulation. Our results indicate that endogenoise cannabinoid are involved in this feedback mechanism though CB1Rs to limit chronic stress-induced hypersensitivity. The activation of serotonin $1 \mathrm{~A}$ could inhibit the visceral motor induced by visceral pain, but had no effect to autonomic cardiovascular of responses to colorectal distension in rats, which imply us peripheral systemic administration might have in adequate central exposure. ${ }^{36}$ So in our research, the modulation effects were mainly due to the activation of peripheral cannabinoid receptors.

Intracolonic pressure of $\leq 20 \mathrm{mmHg}$ would be perceived as non-nociception in normal rats, which pathway to the CNS was different from the nociceptive stimulation. ${ }^{37}$ In our result, 20 $\mathrm{mmHg}$ has no significant changes between groups. Thus we speculated that non-nociception pathway was not involved in the hypersensitivity induced by chronic PR.

\section{Stress-induced up-regulation of CB1R expression in the large and small intestine}

In the present study, involvement of the endogenous cannabinoid system in the modulation of the acute phase of restrain stress-induced hyperalgesia is further supported by the increased levels of transcripts coding for CB1Rs in rats exposed to repeated restraint stress. Recent data indicate a protective function of up-regulated endocannabinoid levels in colitis. ${ }^{38,27}$ In rats and guinea pigs, besides an expression in cholinergic myenteric neurons, a close association between CB1R immunoreactivity and fibers labeled for a synaptic protein has been described, suggesting a role in the modulation of transmitter release. ${ }^{39}$ Similarly, expression of $\mathrm{CB} 1 \mathrm{Rs}$ has been found to be up-regulated in rats during an experimental intestinal inflammation. ${ }^{26,40}$

CB1-deficient mice or wild-type mice treated with the CB1R antagonist Rimonabant display a stronger experimental colitis than controls. ${ }^{26}$ Endocannabinoid levels are also increased in different models of neuropathic pain. ${ }^{41-43}$ It is now well established that $\mathrm{CB} 1 \mathrm{R}$ participate in many aspects of the neuroimmune response triggered by intestinal infection or inflammation.

However, the mechanisms underlying increased CB1R expression observed in association with peripheral inflammation is incompletely understood. Thus, present study show the evidence that neurons that express low levels of CB1Rs in basal conditions start to express this receptor to enhance endocannabinoid signa- ling. These changes may not only serve as potential therapeutic targets for IBS, but also lead to the identification of novel regulatory mechanisms involved in pathophysiology. In the gut, CB1Rs are likely to be activated by the products of inflammation in IBS, and, through its up-regulation, may contribute to feedback mechanism of hypersensitivity. This finding provides evidence that the levels of CB1Rs are strictly related to active hypersensitivity.

The early alterations in abdominal contractile response to colorectal distension of agonist/antagonist treated rats and the increased levels of CB1R mRNA in myenteric plexuses of enhanced sensation colons seem to point to an important, if not predominant, function of the endogenous cannabinoid system at peripheral sites. Use of central administration of drugs or, conversely, of cannabinoid agonists and antagonist unable to cross the blood-brain barrier will help to clarify this important issue.

In conclusion, this study shows the endogenous cannabinoid system is physiologically involved in the protection against excessive hyperalgesia in the colon, strongly suggesting modulation of the physiological activity of the endogenous cannabinoid system during stress might be a promising therapeutic tool for the treatment of several diseases characterized by hyperalgesia of the GI tract.

\section{References}

1. Grispoon L, Bakalar JB. Marijuana, the forbidden medicine. Yale University Press 1997:184.

2. Pinto L, Izzo AA, Cascio MG, et al. Endocannabinoids as physiological regulators of colonic propulsion in mice. Gastroenterology 2002;123:227-234.

3. Di Carlo G, Izzo AA. Cannabinoids for gastrointestinal diseases: potential therapeutic applications. Expert Opin Investig Drugs 2003; 12:39-49.

4. Rice AS, Farquhar-Smith WP, Nagy I. Endocannabinoids and pain: spinal and peripheral analgesia in inflammation and neuropathy. Prostaglandins Leukot Essent Fatty Acids 2002;66:243-256.

5. Mayer EA, Craske M, Naliboff BD. Depression, anxiety, and the gastrointestinal system. J Clin Psychiatry 2001;62(suppl 8):S28-S36.

6. Wood JD, Alpers DH, Andrews PL. Fundamentals of neurogastroenterology. Gut 1999;45(suppl 2):II6-II16.

7. Di Mrazo V. 'Endocannabinoids' and other fatty acid derivatives with cannabimimetic properties: biochemistry and possible physiopathological relevance. Biochim Biophys Acta 1998;1392:153-175.

8. Russo EB. Role of cannabinoids in pain management. In: Weiner RS, ed. Pain management: a practical guide for clinicians. 6th ed. Boca Raton, FL: CRC Press 2002:357-375.

9. Pertwee RG. Cannabinoid receptors and pain. Prog Neurobiol 2001; 63:569-611. 
10. Guindon J, Desroches J, Dani M, Beaulieu P. Pre-emptive antinociceptive effects of a synthetic cannabinoid in a model of neuropathic pain. Eur J Pharmacol 2007;568:173-176.

11. Russo EB. Clinical Endocannabinoid Deficiency (CECD): can this concept explain therapeutic benefits of cannabis in migraine, fibromyalgia, irritable bowel syndrome and other treatment-resistant conditions? Neuro Endocrinol Lett 2008;29:192-200.

12. Baker D, Pryce G, Croxford JL, et al. Cannabinoids control spasticity and tremor in a multiple sclerosis model. Nature 2000;404: 84-87.

13. Zajicek J, Fox P, Sanders H, et al. Cannabinoids for treatment of spasticity and other symptoms related to multiple sclerosis (CAMS study): multicentre randomised placebo-controlled trial. Lancet 2003;362:1517-1526.

14. Wade DT, Robson P, House H, Makela P, Aram J. A preliminary controlled study to determine whether whole-plant cannabis extracts can improve intractable neurogenic symptoms. Clin Rehabil 2003; 17:21-29.

15. Massa F, Storr M, Lutz B. The endocannabinoid system in the physiology and pathophysiology of the gastrointestinal tract. J Mol Med 2005;83:944-954.

16. Sanson M, Bueno L, Fioramonti J. Involvement of cannabinoid receptors in inflammatory hypersensitivity to colonic distension in rats. Neurogastroenterol Motil 2006;18:949-956.

17. Izzo AA, Fezza F, Capasso R, et al. Cannabinoid CB1-receptor mediated regulation of gastrointestinal motility in mice in a model of intestinal inflammation. Br J Pharmacol 2001;134:563-570.

18. Brusberg M, Arvidsson S, Kang D, Larsson H, Lindström E, Martinez V. CB1 receptors mediate the analgesic effects of cannabinoids on colorectal distension-induced visceral pain in rodents. $\mathrm{J}$ Neurosci 2009;29:1554-1564.

19. Gué M, Del Rio-Lacheze C, Eutamene H, Théodorou V, Fioramonti J, Buéno L. Stress-induced visceral hypersensitivity to rectal distension in rats: role of $\mathrm{CRF}$ and mast cells. Neurogastroenterol Motil 1997;9:271-279.

20. Rutkowska M, Fereniec-Gołtbiewska L. ACEA (arachidonyl-2chloroethylamide), the selective cannabinoid $\mathrm{CB} 1$ receptor agonist, protects against aspirin-induced gastric ulceration. Pharmazie 2006; 61:341-342.

21. Massa F, Marsicano G, Hermann H, et al. The endogenous cannabinoid system protects against colonic inflammation. J Clin Invest 2004;113:1202-1209.

22. Ness TJ, Gebhart GF. Colorectal distension as a noxious visceral stimulus: physiological and pharmacological characterization of pseudoaffective reflexes in the rat. Brain Res 1988;450:153-169.

23. Bradesi S, Kokkotou E, Simeonidis S, et al. The role of Neurokinin 1 receptors in the maintenance of visceral hyperalgesia induced by repeated stress in rats. Gastroenterology 2006;130:1729-1742.

24. Schwetz I, Bradesi S, McRoberts JA, et al. Delayed stress-induced colonic hypersensitivity in male Wistar rats: role of neurokinin-1 and corticotropinreleasing factor-1 receptors. Am J Physiol Gastrointest Liver Physiol 2004;286:683-691.

25. Esch T. Endocannabinoid signaling in stress, medicine and wellness. Med Sci Monit 2005;11:ED3-ED5.

26. Massa F, Marsicano G, Hermann H, et al. The endogenous canna- binoid system protects against colonic inflammation. J Clin Invest 2004;113:1202-1209.

27. Di Marzo V, Izzo AA. Endocannabinoid overactivity and intestinal inflammation. Gut 2006;5 5:1373-1376.

28. D'Argenio G, Valenti M, Scaglione G, Cosenza V, Sorrentini I, Di Marzo V. Up-regulation of anandamide levels as an endogenous mechanism and a pharmacological strategy to limit colon inflammation. FASEB J 2006;20:568-570.

29. Holzer P. Gastrointestinal afferents as targets of novel drugs for the treatment of functional bowel disorders and visceral pain. Eur J Pharmaco 2001;429:177-193.

30. Hamamoto DT, Giridharagopalan S, Simone DA. Acute and chronic administration of the cannabinoid receptor agonist CP 55,940 attenuates tumor-evoked hyperalgesia. Eur J Pharmacol 2007;558: 73-87.

31. Gutierrez T, Farthing JN, Zvonok AM, Makriyannis A, Hohmann AG. Activation of peripheral cannabinoid $\mathrm{CB} 1$ and $\mathrm{CB} 2$ receptors suppresses the maintenance of inflammatory nociception: a comparative analysis. Br J Pharmacol 2007;150:153-163.

32. Izzo A.A. Mascolo N, Borrelli F, Capasso F. Exitatory transmission to the circular muscle of the guinea-pig ileum: evidence for the involvement of cannabinoid CB1 receptors. Br J Pharmacol 1998;124: 1363-1368.

33. Yüce B, Kemmer M, Qian G, et al. Cannabinoid 1 receptors modulate intestinal sensory and motor function in rat. Neurogastroenterol Motil 2010;22:672-e205.

34. Myers BS, Martin JS, Dempsey DT, Parkman HP, Thomas RM, Ryan JP. Acute experimental colitis decreases colonic circular smooth muscle contractility in rats. Am J Physiol 1997;273:928-936.

35. Hosseini JM, Goldhill JM, Bossone C, Piñeiro-Carrero V, SheaDonohue T. Progressive alterations in circular smooth muscle contractility in TNBS-induced colitis in rats. Neurogastroenterol Motil 1999;11:347-356.

36. Lindström E, Ravnefjord A, Brusberg M, Hjorth S, Larsson H, Martinez V. The Selective 5 - Hydroxytryptamine 1A antagonist, AZD7371 [3 (R) - (N, N - Dicyclobutylamino) - 8 - fluoro - 3, 4 dihydro - 2H-1-benzopyran-5-carboxamide (R,R)-tartrate Monohydrate] (robalzotan tartrate monohydrate), inhibits visceral pain-related visceromotor, but not autonomic cardiovascular, responses to colorectal distension in rats. J Pharmacol Exp Ther 2009;329: 1048-1055.

37. Mayer EA, Collins SM. Evolving pathophysiologic models of functional gastrointestinal disorders. Gastroenterology 2002;122:20322048.

38. Storr MA, Sharkey KA. The endocannabinoid system and gut-brain signaling. Curr Opin Pharmacol 2007;7:575-582.

39. Coutts AA, Irving AJ, Mackie K, Pertwee RG, Anavi-Goffer S. Localisation of cannabinoid $\mathrm{CB}$ (1) receptor immunoreactivity in the guinea pig and rat myenteric plexus. J Comp Neurol 2002;448: 410-422.

40. Fezza F, Capasso R, Pinto L, et al. Cannabinoid CB1-receptor mediated regulation of gastrointestinal motility in mice in a model of intestinal inflammation. Br J Pharmacol. 2001; 134:563-570.

41. Mitrirattanakul S, Ramakul N, Guerrero AV, et al. Site-specific increases in peripheral cannabinoid receptors and their endogenous li- 
gands in a model of neuropathic pain. Pain 2006;126:102-114.

42. Petrosino S, Palazzo E, de Novellis V, et al. Changes in spinal and supraspinal endocannabinoid levels in neuropahic rats. Neuropharmacology 2007;52:415-422.
43. Agarwal N, Pacher P, Tegeder I, et al. Cannabinoids mediate analgesia largely via peripheral type 1 cannabinoid receptors in nociceptors. Nat Neurosci 2007;10:870-879. 